\title{
Planos de governo dos presidenciáveis: uma análise sobre a abordagem da reforma agrária para a gestão 2019-2022
}

Presidential governance plans: an analysis of the approach to agrarian reform for management 2019-2022

Planes de gobernanza presidenciales: un análisis del enfoque de la reforma agraria para la gestión 2019-2022

Plans de gouvernance présidentielle: une analyse de l'approche de la réforme agraire pour la gestion 2019-2022

\section{João Paulo Pereira Duarte}

\section{(2) OpenEdition}

\section{Journals}

\section{Edição electrónica}

URL: http://journals.openedition.org/espacoeconomia/8676

DOI: $10.4000 /$ espacoeconomia.8676

ISSN: 2317-7837

\section{Editora}

Núcleo de Pesquisa Espaço \& Economia

Refêrencia eletrónica

João Paulo Pereira Duarte, «Planos de governo dos presidenciáveis: uma análise sobre a abordagem da reforma agrária para a gestão 2019-2022 », Espaço e Economia [Online], 16 | 2019, posto online no dia 28 dezembro 2019, consultado o 10 janeiro 2020. URL : http://journals.openedition.org/ espacoeconomia/8676; DOI : 10.4000/espacoeconomia.8676

Este documento foi criado de forma automática no dia 10 janeiro 2020.

(c) NUPEE 


\section{Planos de governo dos presidenciáveis: uma análise sobre a abordagem da reforma agrária para a gestão 2019-2022}

Presidential governance plans: an analysis of the approach to agrarian reform for management 2019-2022

Planes de gobernanza presidenciales: un análisis del enfoque de la reforma agraria para la gestión 2019-2022

Plans de gouvernance présidentielle: une analyse de l'approche de la réforme agraire pour la gestion 2019-2022

João Paulo Pereira Duarte

\section{Introdução}

1 Existente há centenas de anos e ocorrida em quase todos os países do mundo, a reforma agrária é pauta em todos os Estados que praticaram ou praticam a democracia como regime de governo. A questão fundiária é objeto de discussão há muito tempo no Brasil e tem seu desenvolvimento subsidiado pelos sucessivos governos, que, em alguns casos, contribuíram para seu desenvolvimento e, em outros, reforçaram uma regressão, deixando-a no esquecimento.

O conceito de reforma agrária, apesar de abrangente, é de fácil entendimento, visto não haver divergências substanciais entre os estudiosos.

Delgado (2014) diferencia a reforma agrária da questão agrária como conceitos independentes entre si, de tal modo que, enquanto a última se refere à estrutura agrária do país, a reforma acompanha paralelamente políticas públicas que viabilizam uma nova estruturação fundiária do território nacional, essa de uma forma mais justa. 
4 Melgarejo (2001), embasado em estudos, afirma que em algum momento das suas histórias, os países, hoje chamados desenvolvidos, realizaram algum tipo de reforma na questão fundiária de seus territórios, o que resolveu problemas semelhantes aos encontrados no Brasil, causados principalmente por algumas distorções.

5 A reforma possui um objetivo central claro e processo simplório, haja vista a complexidade do assunto. De acordo com Lima (2014), o objetivo é proporcionar uma redistribuição das terras que não cumpram sua função social, ou seja, visa as grandes propriedades que, em boa parte, não estão sendo exploradas, dando ensejo à distribuição dessas terras em lotes para famílias camponesas.

6 Com base na Lei n. 4.504, de 30 de novembro de 1964 (Estatuto de Terra), pode-se definir a reforma agrária como um conjunto de medidas que promovem uma melhor distribuição de terra, por meio de modificações no regime de uso e posse da propriedade, com o intuito de atender aos princípios de justiça social e aumento da produtividade (JUSBRASIL, 2018).

7 O modo de vida dos assentados, para Bourdieu (1989), é constituído em sua busca por sustentabilidade, seja econômica ou social, em uma disputa que se define por meio dos jogos das forças sociais em âmbito local e regional. O termo sustentabilidade pode ser utilizado para embasar as práticas dos novos assentados nas últimas décadas. Através de políticas públicas, essas mundiais, veem nos assentamentos, sejam de quilombolas, indígenas ou sociais, a imposição de uma agricultura mais sustentável ao meio ambiente, tratando-se de uma oportunidade de fomentar e estabelecer a prática.

8 Flores e Macedo (1999) corroboram com essa ideia e expressam o ponto de transformação histórica dessa prática nos planejamentos públicos e intervenções acerca do desenvolvimento rural no país. Ambos afirmam que na segunda metade da década de 1990, esse enfoque ganha importância decisiva, inclusive, com mudança de prioridade, deixando de lado a produtividade-reducionista como principal, para que se adotasse um enfoque mais sustentável, que envolvesse condicionantes ambientais, históricos, sociais, políticos e econômicos.

9 Apesar de estar na Constituição Federal e ser um processo atribuído ao Estado, Mitidiero Júnior (2011) aponta que o Estado, através dos seus governos, não é o único agente da criação dos projetos de assentamentos. Para o citado doutrinador, a sociedade civil organizada em movimentos sociais é quem pressiona o governo para essas realizações. Desta forma, a ineficiência do Estado nas etapas do processo, contribui para o surgimento de movimentos sociais, tal como o MST (Movimento dos Trabalhadores Sem Terra), que lutam por igualdade na distribuição de terras.

10 O referido autor ainda elenca alguns dos principais motivos dessa morosidade do Estado, que implica em problemas para o assentamento, como a lentidão das demandas no âmbito judicial, a demora na demarcação dos lotes e na construção dos imóveis. Outros fatores importantes para a continuação dos programas públicos destinados a questão agrária são a assistência técnica e a comercial, o que está ligado diretamente a eficiência na continuidade dos programas.

11 Ponto de bastante discussão no processo reformista é a desapropriação das terras, pois se leva em conta a função social da terra; contudo, em alguns casos, não houve necessidade de tais atos, tendo em vista que a reforma começou a ser implantado no governo Fernando Henrique Cardoso, onde se foi proposto políticas de assentamentos 
rurais que não tivesse a necessidade de determinações de ações desapropriatórias (SAUER; PEREIRA, 2006).

12 No entanto, em trecho da Constituição Federal de 1988, no artigo 184 deixa claro o processo que se dá para a reforma agrária, ao prever a competência da União para desapropriar por interesse social o imóvel rural que não esteja cumprindo sua função social, assegurando prévia e justa indenização ao proprietário da terra.

13 E diante dessas afirmativas e entendimento que é por meio do Estado que se realiza uma reforma agrária justa, não tirando o papel da sociedade como principal incentivador, é que a pesquisa se fundamenta, levando em conta os planos de governo dos dois candidatos ao pleito de presidente do Brasil (2019-2022) e que chegaram ao segundo turno, analisando suas propostas, ideias e contradições para o tema.

\section{Metodologia}

\section{Levantamento das propostas dos governáveis}

14 No presente trabalho, foi levada em conta a colocação dos candidatos no primeiro turno, sendo incluso, apenas, os dois primeiros colocados e que, consequentemente, disputaram o segundo turno. A pesquisa considerou principalmente os planos de governo apresentado pelos mesmos ao Tribunal Superior Eleitoral (TSE); porém, não deixou de considerar, também, as demais formas de comunicação, como sites dos partidos, sites pessoais dos candidatos, debates televisivos e propaganda eleitoral televisiva.

15 As outras fontes de comunicação eleitoral foram pesquisadas nos meses de agosto, setembro e outubro do ano de 2018, meses estes que antecederam a eleição presidencial objeto da pesquisa.

\section{Cenário Eleitoral}

O recente cenário para o governo do país encontrava-se com 13 candidaturas. Os nomes, números de registro, situação, sigla e coligação destas candidaturas estão em ordem alfabética na tabela abaixo (tabela 1), com base nos dados obtidos junto ao site do TSE; em destaque estão os dois candidatos que ingressaram para o segundo turno.

Tabela 1 - Candidatos à presidência do Brasil

\begin{tabular}{|l|l|l|l|l|}
\hline Nome na Urna & $N^{\circ}$ & Situação & Sigla & Partido/Coligação \\
\hline ALVARO DIAS & 19 & Deferido & PODE & MUDANÇA DE VERDADE \\
\hline CABO DACIOLO & 51 & Deferido & PATRI & PATRI \\
\hline CIRO GOMES & 12 & Deferido & PDT & BRASIL SOBERANO \\
\hline EYMAEL & 27 & Deferido & DC & DC \\
\hline GERALDO ALCKMIN & 45 & Deferido & PSDB & PARA UNIR O BRASIL \\
\hline
\end{tabular}




\begin{tabular}{|l|l|l|l|l|}
\hline GUILHERME BOULOS & 50 & Deferido & PSOL & VAMOS SEM MEDO DE MUDAR O BRASIL \\
\hline HENRIQUE MEIRELLES & 15 & Deferido & MDB & ESSA É A SOLUÇÃO \\
\hline JAIR BOLSONARO & $\mathbf{1 7}$ & Deferido & PSL & BRASIL ACIMA DE TUDO, DEUS ACIMA DE TODOS \\
\hline JOÃO AMOÊDO & 30 & Deferido & NOVO & NOVO \\
\hline JOÃO GOULART FILHO & 54 & Deferido & PPL & PPL \\
\hline FERNANDO HADDAD & $\mathbf{1 3}$ & Deferido & PT & O POVO FELIZ DE NOVO \\
\hline MARINA SILVA & 18 & Deferido & REDE & UNIDOS PARA TRANSFORMAR O BRASIL \\
\hline VERA & 16 & Deferido & PSTU & PSTU \\
\hline
\end{tabular}

Fonte: TSE, 2018

\section{Bases para as análises dos planos de governo}

Os Planos serão confrontados com uma agenda idealizada por bases nacionais e internacionais de especialistas do mundo todo e do Brasil, que sugerem propostas fortes e transitórias à estrutura fundiária brasileira. Projetos e programas que mesmo que de forma inconsciente corroboram com as ideias que serão apresentadas, servirão para aplicação na análise qualitativa, que será empregada de forma coerente e imparcial, por meio da tabela 2 .

19 A tabela de pontuação abaixo servirá como indicador de comparação e análise dos planos de governo pesquisados. Para tanto, foram criados tópicos temáticos que favorecem um clareamento da discussão. Cada tema recebeu uma pontuação, modificando de acordo com a importância do mesmo, bem como sua similaridade com a pesquisa em questão. A metodologia aplicada não limita a quantidade de projetos por tópicos, sendo, portanto, a pontuação livre sem teto estipulado.

Tabela 2 - Tabela de pontuação metodológica.

\begin{tabular}{|c|c|}
\hline \multicolumn{2}{|l|}{ Tabela de pontuação } \\
\hline Citação (Reforma Agrária, Questão agrária, Assentamentos) & 0,5 \\
\hline Projetos que envolvam a Reforma Agrária & 1,0 \\
\hline $\begin{array}{l}\text { Estabilidade do processo, Fiscalização e assistência técnica e comercial para assentados e } \\
\text { futuros assentamentos }\end{array}$ & 1,5 \\
\hline Projetos específicos de reforma agrária & 1,5 \\
\hline Ausência de propostas na área & $-0,5$ \\
\hline
\end{tabular}

Fonte: Elaborada pelo autor (2018) 


\section{Citações} das seguintes palavras nos planos de governo contidos no site do TSE: Reforma Agrária e Assentamentos. Não serão computados casos onde o título contém alguma palavra e no parágrafo subsequente referente ao título se encontre a mesma palavra.

presença, exclusivamente, dessas agendas nos planos de governo mostra a mínima atenção aos mesmos. Outro ponto relevante refere-se à contextualização da palavra que acarreta consigo unanimemente discussões sobre o tema.

\section{Projetos que envolvam a Reforma Agrária}

A simples criação de um projeto voltado aos assentados ou a reforma em si computará 1,0 ponto ao candidato.

Estabilidade do processo, fiscalização e assistência técnica e comercial para assentados e futuros assentamentos.

Políticas públicas voltadas a fiscalização de terras que não cumpram sua função social, fomento à reforma, e assistência técnica voltada para continuidade dos assentados, bem como programas, créditos para a comercialização de produtos advindo de assentados da reforma agrária. Pontuação de 1,5 para cada.

Projetos que possuam um viés reformista em qualquer camada social ou territorial. De forma direta ou indireta, por meio de financiamentos, incentivos, programas, ou vertente pedagógica. Equivalente a 1,5 pontos.

Ausência de propostas na área.

Amples ausência de programas voltados aos temas centrais das pesquisas em todas as formas de comunicação das propostas dos governantes, acarretarão a perda de meio ponto no rankeamento proposto por esse projeto. Portanto, valendo (-) 0,5 pontos.

\section{Resultado Eleitoral}

No dia 28 de outubro de 2018, foi eleito como novo presidente da República Federativa do Brasil Jair Bolsonaro, candidato do PSL, com 55,13\% dos votos válidos, ante $44,87 \%$ do candidato do PT, como exposto no gráfico abaixo. 
Gráfico 1. Resultado da eleição presidencial 2018.

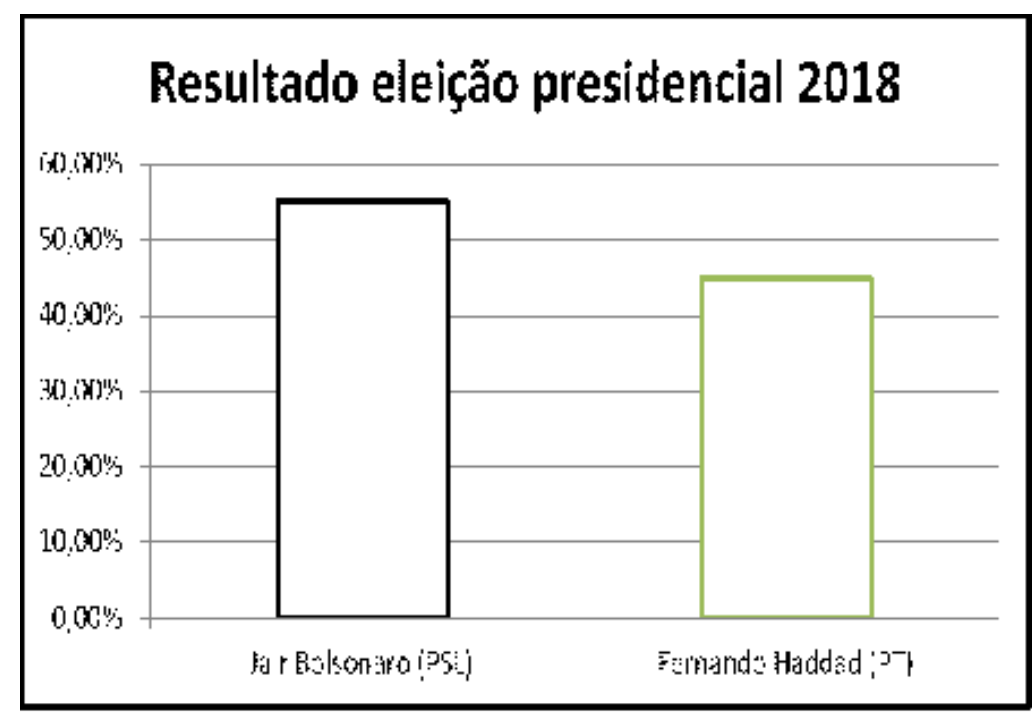

Fonte: Elaborado pelo autor (2018)

31 Para fins de presente pesquisa, não será analisado apenas o plano de governo do presidente eleito, Jair Bolsonaro, e que supostamente será posto em prática durante seu governo nos próximos quatro anos, mas também de seu concorrente, Fernando Haddad, o qual teve votação expressiva, com mais de 47 milhões de brasileiros apoiando sua candidatura.

\section{RESULTADOS E DISCUSSÕES}

\section{Plano de Governo do Partido dos Trabalhadores - PT, Coligação (PT - PcdoB - PROS)}

Logo na página 8 do plano de governo do Partido dos Trabalhadores, o termo "democratizar" a propriedade de terra aparece, sugerindo que isso ocorra diante de uma reforma agrária, já mostrando inicialmente que o partido se põe como a favor da reforma. Nesse contexto, o plano apresenta a reforma agrária como uma das três dimensões essenciais à transição ecológica, o que mostra a importância dada ao tema, pois a transição ecológica serve como um dos temas centrais do plano de governo.

o partido acredita, embasado na Constituição Federal, que a reforma agrária, como inserida nas pautas de direito civil, político, econômico, social, cultural e ambiental, somente será conquistada enfrentando o Estado de exceção seletivo formado pelo governo Temer, de tal modo que somente assim seriam combatidas as desigualdades sociais.

Art. 184. Compete à União desapropriar por interesse social, para fins de reforma agrária, o imóvel rural que não esteja cumprindo sua função social, mediante prévia e justa indenização em títulos da dívida agrária, com cláusula de preservação do valor real, resgatáveis no prazo de até vinte anos, a partir do segundo ano de sua emissão, e cuja utilização será definida em lei (BRASIL, 1988). 
A Constituição Federal prevê a reforma agrária, e, basicamente, após a desapropriação de terra, a mesma é redistribuída de acordo com uma listagem das famílias mais pobres que viverão da terra, diminuindo assim, a ideia de desigualdade.

Já o Estado de exceção citado pelo plano de governo se parece mais com uma espécie de "ataque" ao recente governo que sucedeu o governo Dilma (também do PT) e que sofreu o impeachment no ano de 2016. Um Estado de exceção é o oposto de um estado democrático de direito, e é decretado geralmente em situações de emergência pelas autoridades, como afirmam Gomes e Matos (2017), sugerindo que o Estado de exceção seria uma medida excepcional em relação a legalidade, sendo assim, autorizado pelo ordenamento apenas diante de situações emergenciais. E essa possível realidade poderiam acarretar, entre vários fatores, a calamidade pública e a desordem constitucional democrática; porém, apesar de não serem objeto da presente pesquisa discussões acerca da qualidade e eficiência do governo Temer, a democracia, do nosso ponto de vista não foi ameaçada, nem mesmo de forma oculta.

No final da página 22, após a titulação da promoção dos direitos dos povos do campo, das águas e florestas, o governo se compromete novamente a realizar a reforma agrária entre outros pontos, como por exemplo, a titulação de terras quilombolas e a demarcação de terras indígenas, o que promoveria na visão do partido uma maior dignidade humana e o viver bem.

Para a candidatura do governo Haddad, seria fundamental a elaboração de uma nova política, essa chamada de "Política Nacional de Desenvolvimento Regional e Territorial", ou PDRT, que surgiria com o objetivo de interiorização das oportunidades de inclusão produtiva, bem como a redução das desigualdades. Para isso, seria necessário mobilizar associações e cooperativas fundadas na diversidade ambiental e social, na economia solidária e na produção artesanal, ou seja, que tenha uma ideia de desenvolvimento semelhantes as do partido, possivelmente excluindo as que não se adequem a essa vertente ideológica central.

Ainda de acordo com a política, isso envolveria povos do campo (compreendendo os assentados da reforma agrária), além dos povos das florestas, das águas e também da agricultura familiar, sendo valorizada a economia dos pequenos negócios e as cooperativas e as incubadoras de pesquisas locais.

Há neste ponto uma clara preferência dado pelo partido aos "pequenos agricultores", em sua maioria beneficiados pelo governo através de programas e políticas públicas e que necessitam de um serviço de apoio, além da continuidade no auxílio. Isso se dá, principalmente, pelas posições próprias do partido contrárias ao aumento no uso de agrotóxicos, através da defesa de leis mais severas à disponibilidade e comercialização dos mesmos no país, com vistas à justiça social no campo. 0 partido notadamente defende uma reforma agrária que traria o fim dos latifúndios, por vezes improdutivos, e uma consequente suposta redução na desigualdade social.

E seriam através desses povos que o governo conseguiria impor algumas demandas que se opõem às ideias citadas acima, como por exemplo, uma agricultura mais sustentável, sem uso de agroquímicos, em consonância com a conservação do meio ambiente, entre outros fatores que ficam explícitos nas propostas expressas pelo plano e que foram corroboradas em debates pelo então candidato Fernando Haddad.

presidente Michel Temer, que dispõe sobre a regularização fundiária rural e urbana: 
Dispõe sobre a regularização fundiária rural e urbana, sobre a liquidação de créditos concedidos aos assentados da reforma agrária e sobre a regularização fundiária no âmbito da Amazônia Legal; institui mecanismos para aprimorar a eficiência dos procedimentos de alienação de imóveis da União; altera as Leis $n^{\text {os }} 8.629$, de 25 de fevereiro de 1993,13.001, de 20 de junho de 2014, 11.952, de 25 de junho de 2009, 13.340, de 28 de setembro de 2016, 8.666, de 21 de junho de 1993, 6.015, de 31 de dezembro de 1973, 12.512, de 14 de outubro de 2011,10.406, de 10 de janeiro de 2002 (Código Civil), 13.105, de 16 de março de 2015 (Código de Processo Civil), 11.977, de 7 de julho de 2009, 9.514, de 20 de novembro de 1997, 11.124, de 16 de junho de 2005, 6.766, de 19 de dezembro de 1979, 10.257, de 10 de julho de 2001,12.651, de 25 de maio de 2012, 13.240, de 30 de dezembro de 2015,9.636, de 15 de maio de 1998, 8.036, de 11 de maio de 1990, 13.139, de 26 de junho de 2015, 11.483, de 31 de maio de 2007, e a 12.712, de 30 de agosto de 2012, a Medida Provisória no 2.220, de 4 de setembro de 2001, e os Decretos-Leis nos 2.398, de 21 de dezembro de 1987, 1.876, de 15 de julho de 1981, 9.760, de 5 de setembro de 1946, e 3.365, de 21 de junho de 1941; revoga dispositivos da Lei Complementar no76, de 6 de julho de 1993, e da Lei no 13.347, de 10 de outubro de 2016; e dá outras providências (BRASIL, 2017).

Segundo Amadei, Pedroso e Filho (2017), a nova lei trouxe uma mudança de paradigma em relação ao trato da regularização imobiliária, e, com isso, mudou também o sentido da expressão "regularização fundiária", antes aplicada somente no âmbito da titulação, em especial ao imóvel rural, no âmbito do Direito Agrário, atualmente como gênero de uma pluralidade de medidas de intervenções públicas frente aos diversos aspectos irregulares, como por exemplo, a falta de titulação às desordenadas formas de habitação, quer seja de empreendimentos e imóveis rurais, ou de empreendimentos de imóveis urbanos, podendo ser na esfera da propriedade privada ou de domínio público.

43 Ainda de acordo com os citados estudiosos, a lei é fruto de um descaso por parte do Estado com o uso da terra pelo povo, pois o aumento de ocupações irregulares, clandestinas e desorganizadas teria sido facilitada por um Estado fraco em relação à fiscalização e observância dos nortes legais baseados pelo legislador, não havendo dúvidas acerca da criação de novos mecanismos para amenizar o descompasso entre a situação fática e a realidade registral, proporcionando instrumentos de regularização da ocupação pelos ocupantes (AMADEI; PEDROSO; FILHO, 2017).

Contudo, apesar da sinalização positiva dos autores, outros setores da sociedade e especialistas se posicionaram em contraposição a regularização. A Lei n.. 13.465/17, antiga Medida Provisória n.. 759, mudou alguns aspectos fundamentais para a regularização fundiária rural. Diante disso, pesquisadores e movimentos sociais afirmam que a nova legislação facilita a concentração fundiária, a grilagem ${ }^{1}$ de terras, bem como acaba com os critérios que asseguravam a função social da terra (TERRA DOS DIREITOS, 2017).

Outras entidades se posicionaram contra a medida e posteriormente à lei em sua totalidade ou em partes, como o Conselho Nacional de Direitos Humanos - CNDH, a Associação Nacional dos Defensores Públicos - ANADEP, a Federação Nacional dos Arquitetos e Urbanistas - FNA, e, também, o FNRU - Fórum Nacional da Reforma Urbana, além de uma proposta de ação direta de inconstitucionalidade por parte da Procuradoria Geral da República e outra do próprio Partido dos Trabalhadores (PT).

Ou seja, instituições respeitadas e pessoas de renome na área foram contrárias em partes ou na sua totalidade à referida Medida Provisória, que fere, principalmente, o conceito de função social da terra, critério sine qua non atualmente para a continuidade da reforma agrária no país. Porém, o principal ponto a ser observado foi a falta de 
debate e a dissociação da sociedade representada pelos movimentos no processo, sendo positiva a iniciativa petista de pelo menos abrir um debate acerca da revogação da lei, vigente nos dias de hoje.

No tópico de título "Viver bem no campo", o plano de governo petista prevê diversas orientações que culminam numa agricultura mais sustentável para produção de alimentos mais saudáveis. Essa ideia se embasa não apenas na vertente ideológica da coligação, mas também em organizações mundiais, como a FAO - Organização das Nações Unidas para Alimentação e Agricultura - da ONU, sugerindo-se "uma extensão rural dos bens e serviços que, muitas vezes, limitam-se às cidades".

Isso se conecta diretamente com a reforma agrária, quando seus assentados são inclusos nos "povos" em que o governo implantaria tais práticas. Para se ter uma ideia, no parágrafo subsequente o plano é claro ao afirmar que entende que o papel do Poder Público é fundamental na democratização do acesso a terras rurais e urbanas, ou seja, se coloca em pauta novamente a reforma agrária, com base no ordenamento do uso do solo e da água na proteção da biodiversidade, regulando democraticamente os recursos naturais.

Dando prosseguimento ao tema, na página 56, o ponto acima é corroborado com o subtítulo de "Democratização da terra e reforma agrária", que se inicia com um apelo histórico, rememorando o período não só colonial, mas também do regime militar onde se praticava o doar terras a pessoas ligadas ao rei e ao governo, respectivamente.

Para o PT a democratização do acesso à terra e o fortalecimento da agricultura familiar visa estimular "a ruralização voluntária", o que se opõe a "urbanização forçada". Esse ponto é de suma importância, haja vista que, segundo especialista de diversas áreas (segurança pública, saúde pública, entre outras), a logística reversa do êxodo rural acarretaria benefícios nas cidades.

51 Para uma melhor percepção, Camarano e Abramovay (1998) afirmam que as migrações causam grande impacto não só no meio social como no ambiental. As consequências mais claras são a expansão das áreas urbanas, que acarreta desemprego, violência e aumento de favelas. Outro fator discutido nos últimos anos é o desinteresse dos jovens agricultores de permanecerem nas propriedades agrícolas, o que permite um abandono do campo futuramente (EVANGELISTA; CARVALHO, 2001).

O governo, se eleito fosse, colocaria a reforma agrária no centro da agenda pública nacional, onde seria promovida a atualização dos parâmetros de aferição da função social da terra rural prevista na Constituição, levando em conta não só a produtividade econômica, (como muitas vezes se é feito), mas também de forma mais incisiva a legislação ambiental e trabalhista. Assim, caso a propriedade não estivesse de acordo com essas legalidades, seria cabível a desapropriação.

Outro fator que influiria diretamente aos assentados e futuros assentados seria a reformulação do ITR (Imposto Territorial Rural), que transformaria o tributo regulatório em caráter progressivo no tempo, o que, para o governo, de forma positiva, desestimularia o processo especulativo, as práticas predatórias ao meio ambiente e a aquisição de terras por estrangeiros.

54 Na página 57, o plano indica o atendimento de direitos socias aos povos do campo, como saúde, educação, moradia digna, saneamento, iluminação, transporte e atrativos culturais, de esporte e de lazer, bem como internet barata e acessível em todos os 
lugares; mas sem detalhes específicos de como os faria, deixando apenas uma conotação propositiva.

Na última referência do tema no plano de governo de Fernando Haddad, os assentados da reforma agrária aparecem no contexto da transição ecológica, bastante defendida e pauta base do plano. Ao mencionar a Amazônia, cita a capacidade ambiental e econômica da maior floresta tropical do mundo e elenca seus povos novamente, afirmando sua suposta valorização, que teria papel fundamental na integração sulamericana.

Essa transição possibilitaria o enfrentamento ao desmatamento, às atividades madeireiras e queimadas ilegais, entre outras, novamente mostrando a associação clara dos povos mais excluídos da sociedade (como indígenas, quilombolas e assentados) com a proteção do meio ambiente e adoção de práticas mais sustentáveis, não prevalecendo a vontade do indivíduo, e sim, uma agenda ideológica conservacionista em relação ao meio ambiente. Por fim, asseguraria às mulheres a titularidade prioritária de lotes de assentamentos, isto é, a mulher teria prioridade em relação aos homens ao obter a posse como proprietária dos lotes distribuídos.

\section{Plano de Governo do Partido Social Liberal - PSL, Coligação (PSL - PRTB)}

Logo na página 4 do plano de governo do então candidato Jair Bolsonaro, o termo "propriedade privada", que se encontra em destaque em caixa alta, é apresentado como bem "sagrado", não podendo a mesma ser tomada, invadida ou, até mesmo, expropriada, que significa desapossar o imóvel do dono.

Na página 69, por sua vez, intitulada de AGRICULTURA - Grandes demandas são elencadas seis fatores importantes relacionados à agricultura, entre eles destacando-se a "solução para a questão agrária", contudo, sem especificar a forma com que haveria tal solução, sendo ponto falho no plano de governo do PSL.

O tema reforma agrária sequer é citado no plano de governo. Essa ausência pode ser vista como um sinal de alerta aos que defendem a reforma, a criminalização de movimentos sociais ligados ao tema, bem como a defesa da propriedade privada. Não considerar fatores como o cumprimento da função social da terra, indicaria uma regressão no processo reformista.

Outro ponto importante encontrado no plano de governo é a proximidade do partido e candidato com a bancada ruralista, representante do interesse do grande agronegócio. Ainda na página 4 , há um trecho em que se afirma existir "uma só porta para atender as demandas do agro e do setor rural", o que sugere um modelo de agricultura vinculado a produção de commodities², tendo como base principalmente a "revolução verde"

61 E é notório que isso se contrapõe ao que hoje é tido como atividade principal da agricultura familiar e assentamentos da reforma agrária, práticas mais sustentáveis com menos uso de agrotóxicos, subsidiadas pelo governo nas últimas gestões por meio de políticas públicas como o PAA (Programa de aquisição de alimentos), PNAE (Programa nacional de alimentação escolar) e o PRONAF (Programa de fortalecimento da agricultura familiar), que fomentam agriculturas mais limpas e sustentáveis. 


\section{Classificação dos planos de governo}

O gráfico na sequência ilustra em números a presença do tema da reforma agrária nos planos de governo dos então candidatos do PSL e do PT, composto por fatores expressados na tabela 2.

Gráfico 2. Resultados finais dos programas.

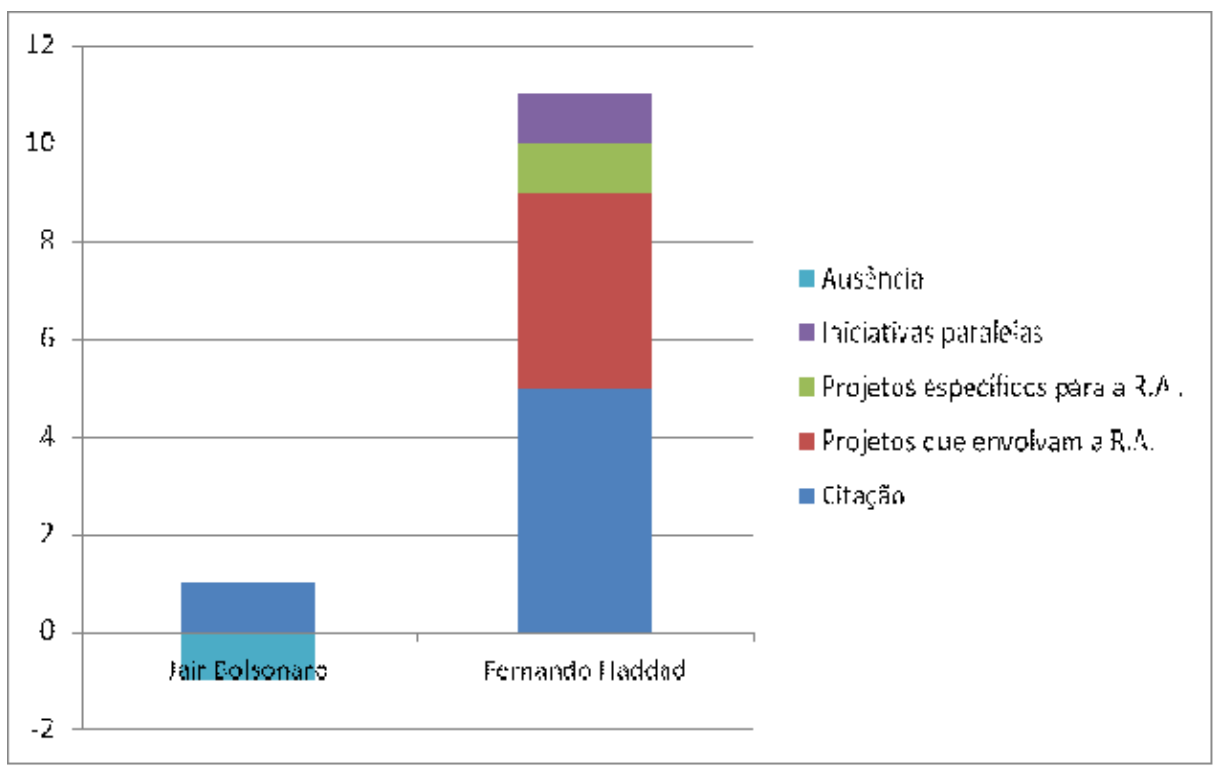

Fonte: Elaborado pelo autor (2018)

63 Nota-se que há falta considerável de projetos e programas voltados especificamente para a reforma agrária em ambos os planos. No plano do presidente eleito do PSL, houve apenas uma citação do tema, porém, sem detalhes no entorno. A ausência clara de proposta para a realização da reforma e defesa dos já assentados proporcionou pontuação 0 (zero), devido à perda de (-) 0,5 pontos pela ausência de abordagem.

Por outro lado, o plano petista buscou em diversos momentos a clareza no fomento da reforma agrária e a defesa não só dos assentados, mas também de movimentos sociais que lutam pela casa própria. Alguns programas são apresentados de forma mais detalhada, outros de forma mais superficial, porém, que concederam 11 (onze) pontos ao plano de governo petista, de acordo com metodologia estabelecida.

\begin{tabular}{|l|l|}
\hline \multicolumn{2}{|l|}{ CONVERGÊNCIA } \\
\hline PSL & PT \\
\hline \multicolumn{2}{|l|}{ A questão agrária é apresentada como pauta importante em ambos os planos de governo. } \\
\hline
\end{tabular}

\begin{tabular}{|l|l|}
\hline DIVERGÊNCIA \\
\hline PSL & PT \\
\hline
\end{tabular}




\begin{tabular}{|l|l|l|}
\hline o plano de governo do PSL presa de & O plano do PT sugere revogação das leis que \\
forma incisiva pela propriedade & criminalizam como terroristas movimentos sociais, tais \\
privada, propondo a criminalização & como o MST, e prega acima de tudo a função social da \\
de movimentos sociais que, & $\begin{array}{l}\text { terra, além das legalidades trabalhistas e ambientais, } \\
\text { supostamente, poderiam causar atos } \\
\text { de terrorismo. }\end{array}$ & $\begin{array}{l}\text { exendo, assim, o processo reformista de } \\
\text { desapropriação de terras para posteriormente } \\
\text { redistribuí-las. }\end{array}$ \\
\hline
\end{tabular}

\section{CONCLUSÃO}

65 A disparidade encontrada em ambos os planos de governo foi grande em relação ao tema abordado, haja vista a rapidez na análise do plano de governo do presidente eleito Jair Messias Bolsonaro, onde o tema não é discutido, bem como pouco é citado, faltando profundidade quando o mesmo ocorre.

Por sua vez, o plano de governo do Partido dos Trabalhadores, apesar de prevalecer a ideologia do partido e apresentar situações infundadas da realidade nacional, em diversos pontos do texto fomenta uma reforma agrária, apresentada como necessária na visão dos petistas. Os termos "democratização da terra" e "regularização fundiária" são bastante empregados, notando um incômodo com o atual cenário brasileiro. Outro ponto indireto explorado são as manifestações sociais que englobam diretamente movimentos sociais (como o MST e MTST), que tem como objetivo central a justa distribuição de imóveis rurais e urbanos, ressaltando uma possível ameaça de o novo governo criminalizá-los como possíveis terroristas.

Portanto, conclui-se ser indiscutível não só devido à preocupação e aos projetos voltados ao tema, mas também pelo debate e discussões apresentadas, que o plano de governo do candidato do PT, Fernando Haddad, demonstrou ser mais completo e qualificado no que se refere à Reforma Agrária no Brasil.

\section{BIBLIOGRAFIA}

BRASIL. Lei n. 4.504, de 30 de novembro de 1964. Dispõe sobre o Estatuto da Terra, e dá outras providências. Disponível em: http://www.planalto.gov.br/ccivil_03/leis/14504.htm. Acesso em 20 de set. de 2018.

AMADEI, Vicente de Abreu; PEDROSO, Alberto Gentil de Almeida; MONTEIRO FILHO, Ralpho Waldo de Barros. Primeiras impressões sobre a Lei no 13.465/2017. ARISP. São Paulo: 2017. Disponível em: http://www.arisp.com.br/lei_n13465_2017.pdf. Acesso em 5 de dez. 2018.

BRASIL. Constituição Federal da República Federativa do Brasil de 1988. Capítulo III - Da política agrícola e fundiária e da reforma agrária, Art. 184. Disponível em: http:// www.planalto.gov.br/ccivil_03/constituicao/constituicao.htm. Acesso em: 10 de dez. 2018. 
BOURDIEU, Pierre. O Poder Simbólico. Rio de Janeiro: Bertrand e Brasil, 1989. Disponível em: http://lpeqi.quimica.ufg.br/up/426/o/BOURDIEU__Pierre._O_poder_simb\%C3\%B3lico.pdf. Acesso em: 02 de out. de 2018.

CAMARANO, Ana Amélia; ABRAMOVAY, Ricardo. Êxodo rural, envelhecimento e masculinização no Brasil: panorama dos últimos cinquenta anos. Rio de Janeiro, 1999. Disponível em: http://www.ipea.gov.br/portal/index.php?

option=com_content\&view=article\&id=3929. Acesso em: 12 de nov. 2018.

DELGADO, Guilherme Costa. Questão agrária hoje. In: Agricultura familiar brasileira: desafios e perspectivas de futuro. Brasília: Ministério do Desenvolvimento Agrário, 2017. p. 14-23. Disponível em: http://portalsiget.net/archivosSIGET/publicaciones/Archivos/ 232017_AFBRASILDesafiosePer.pdf. Acesso em: 15 nov. 2018.

EVANGELISTA, Francisco Raimundo; CARVALHO, José Maria Marques de. Algumas considerações sobre o êxodo rural no nordeste. Fortaleza: ETENE/BNB, 2001. Disponível em: http://www.bnb.gov.br/content/Aplicacao/ETENE/Rede_Irrigacao/Docs/Algumas\%20C onsideracoes\%20sobre\%20o\%20Exodo\%20Rural\%20no\%20Nordeste.PDF. Acesso em: 14 de nov. 2018

FLORES, Murilo Xavier; MACÊDO, Manoel Moacir Costa. Novos Rumos de Desenvolvimento Rural. In: AGUIAR, D.R.D. e PINHO, J.B. (eds). Anais do XXXVII Congresso Brasileiro de Economia e Sociologia Rural. Foz do Iguaçu, SOBER, 1999.

GOMES, Ana Suelen Tossige; MATOS, Andityas Soares de Moura Costa. 0 estado de exceção no Brasil republicano. Rev. Direito e Práxis, Rio de Janeiro, Vol. 08, n. 03, 2017, p. 1760-1787. Disponível em: http://www.scielo.br/pdf/rdp/v8n3/2179-8966-rdp-8-3-1760.pdf. Acesso em 14 de out. de 2018.

GRAZIANO, José da Silva. 0 que é a questão agrária?. São Paulo: Brasiliense, 1985. Disponível em: http://araguaia2.ufmt.br/professor/disciplina_arquivo/16/20131211135.pdf. Acesso em: 12 de set. de 2018.

LIMA, Waldir Coutinho. Políticas públicas para reforma agrária, desafios e possibilidades: Estudo de caso do Assentamento Euclides Neto em Mata de São João Bahia. Monografia de especialização. Universidade Tecnológica Federal do Paraná (UTFPR), Medianeira, 2014. Disponível em: http://repositorio.roca.utfpr.edu.br/jspui/handle/1/4599. Acesso em 21 de out. de 2018.

MELGAREJO, Leonardo. O desenvolvimento, a reforma agrária e os assentamentos - Espaços para a contribuição de todos. In: Agroecologia e Desenvolvimento Rural Sustentável, Porto Alegre, v.2, n.4, out./dez.2001. Disponível em: http://www.emater.tche.br/docs/agroeco/revista/ ano2_n4/revista_agroecologia_ano2_num4_parte14_artigo.pdf. Acesso em: 23 de set. de 2018.

MITIDIERO JÚNIOR, Marco Antônio. Reforma agrária no Brasil: algumas considerações sobre a materialização dos assentamentos rurais. Revista Agrária, São Paulo, n. 14, p. 04-22, 2011. Disponível em: http://www.ccen.ufpb.br/ppgg/contents/producao-docente/marco-antoniomitidiero-junior/marco-revista-usp.pdf. Acesso em: 16 de out. de 2018.

SAUER, Sérgio; PEREIRA, João Márcio Mendes. Capturando a terra: Banco Mundial, políticas fundiárias neoliberais e reforma agrária de mercado. São Paulo: Expressão Popular, 2006.

Terra de Direitos. 10 perguntas e respostas sobre a nova lei de regularização fundiária urbana, 2017. Disponível em: https://terradedireitos.org.br/noticias/noticias/10-perguntas-e-respostassobre-a-nova-lei-de-regularizacao-fundiaria-urbana/22705. Acesso em: 08 de dez. 2018. 
TSE. Brasil acima de tudo, Deus acima de todos. 2018. Disponível em: http://www.tse.jus.br/ eleicoes/eleicoes-2018/propostas-de-candidatos. Acesso em: 12 de set. 2018.

TSE. O povo feliz de novo. 2018. Disponível em: http://www.tse.jus.br/eleicoes/eleicoes-2018/ propostas-de-candidatos. Acesso em 12 de set. 2018.

\section{NOTAS}

1. Falsificação de documentos por meio de prática irregular de colocar documentos falsos em gavetas com grilos que através das fezes dos mesmos, causavam no documento um efeito gradual de envelhecimento

2. São produtos produzidos em larga escala, que podem funcionar como matéria-prima, podendo estes, serem estocados sem perder a qualidade, como por exemplo: soja e café.

3. Nome dado no ano de 1966 ao conjunto de tecnologias que aumentou consideravelmente a produção de alimentos, bem como a utilização de produtos agrotóxicos.

\section{RESUMOS}

A questão agrária é tema de discussão há décadas no Brasil, desde o regime militar até a redemocratização e, dada sua importância e relevância para a política brasileira, permeia debates em todos os governos. Nos dias atuais, o desenvolvimento de reformas agrárias fica subordinado à gestão momentânea, tendo em vista sua dependência de subsídios estatais. Diante desse cenário, a proposta da presente pesquisa foi compreender e analisar a abordagem do tema nos planos de governo de 02 (dois) candidatos que concorreram à presidência do Brasil (inclusive em segundo turno) para mandado presidencial de 2019 a 2022: Jair Messias Bolsonaro (PSL) e Fernando Haddad (PT). Para isso, a pesquisa abordou suas respectivas propostas, ideias e contradições para o tema, tendo sido encontrada grande disparidade em ambos os planos de governo, verificada, sobretudo, pela ausência de abordagem do tema no plano de governo do presidente eleito, Jair Messias Bolsonaro, motivo pelo qual se conclui que o plano de governo do candidato do PT, Fernando Haddad, demonstrou ser mais completo e qualificado no que se refere à reforma agrária no Brasil.

The agrarian question has been the subject of discussion for decades in Brazil, from the military regime to the democratization process, and given its importance and relevance to Brazilian politics, it permeates debates in all governments. Nowadays, the development of agrarian reforms is subordinate to the momentary management, in view of its dependence on state subsidies. Faced with this scenario, the proposal of this research was to understand and analyze the approach of the subject in the government plans of 02 (two) candidates who ran for the presidency of Brazil (including in the second round) for election warrant 2019 a 2022: Jair Messias Bolsonaro (PSL) and Fernando Haddad (PT). To this end, the research addressed their respective proposals, ideas and contradictions to the subject, and found great disparity in both government plans, verified, mainly, by the lack of approach to the topic in the government plan of the elected president, Jair Messias Bolsonaro, reason why it is concluded, in the end, that the government 
plan of the PT candidate, Fernando Haddad, proved to be more complete and qualified when it comes to agrarian reform in Brazil.

La cuestión agraria ha sido discutida durante décadas en Brasil, desde el régimen militar hasta el proceso de democratización, y dada su importancia y relevancia para la política brasileña, impregna los debates de todos los gobiernos. Hoy en día, el desarrollo de las reformas agrarias está subordinado a la gestión momentánea, dada su dependencia de los subsidios públicos. Frente a este escenario, la propuesta de esta investigación fue comprender y analizar el enfoque del sujeto en los planes del gobierno de 02 (dos) candidatos que se postularon para la presidencia de Brasil (incluida la segunda vuelta) para un período electoral de 2019 a 2022: Jair Messias Bolsonaro (PSL) y Fernando Haddad (PT). Con este fin, la investigación examinó sus respectivas propuestas, ideas y contradicciones sobre el tema, y encontró una gran disparidad en los dos planes de gobierno, verificada, principalmente, por la falta de enfoque del tema en el plan de gobierno del presidente electo. Jair Messias. Bolsonaro, por lo que se concluye, finalmente, que el plan de gobierno del candidato del PT, Fernando Haddad, ha demostrado ser más completo y calificado en la reforma agraria en Brasil.

La question agraire fait l'objet de discussions depuis des décennies au Brésil, du régime militaire au processus de démocratisation, et compte tenu de son importance et de sa pertinence pour la politique brésilienne, elle imprègne les débats de tous les gouvernements. De nos jours, le développement des réformes agraires est subordonné à la gestion momentanée, compte tenu de sa dépendance vis-à-vis des subventions publiques. Face à ce scénario, la proposition de cette recherche était de comprendre et d'analyser l'approche du sujet dans les plans du gouvernement de 02 (deux) candidats qui se sont présentés à la présidence du Brésil (y compris au second tour) pour un mandat électoral 2019 à 2022 : Jair Messias Bolsonaro (PSL) et Fernando Haddad (PT). À cette fin, la recherche a examiné leurs propositions, idées et contradictions respectives sur le sujet, et a constaté une grande disparité dans les deux plans gouvernementaux, vérifiée, principalement, par le manque d'approche du sujet dans le plan gouvernemental du président élu, Jair Messias. Bolsonaro, raison pour laquelle il est conclu, finalement, que le plan gouvernemental du candidat PT, Fernando Haddad, s'est révélé plus complet et qualifié en matière de réforme agraire au Brésil.

\section{ÍNDICE}

Palavras-chave: Espaço social, território, reforma agrária, economia política

Palabras claves: Espacio social, territorio, reforma agraria, economía política

Mots-clés: Espace social, territoire, réforme agraire, économie politique

Keywords: social space, territory, agrarian reform, political economy

\section{AUTOR}

\section{JOÃO PAULO PEREIRA DUARTE}

Faculdade Doutor Francisco Maeda - FAFRAM. Engenheiro Agrônomo. Email: joaopaulod917@gmail.com 